\title{
The public in public health
}

\section{Diyanath Samarasinghe}

Former Associate Professor in Psychiatry, Faculty of Medicine, University of Colombo \& Former Chairman, National Dangerous Drugs Control Board, Sri Lanka

Correspondence: 1dsamara@gmail.com (iD https://orcid.org/0000-0003-2891-8297

DOI: https://doi.org/10.4038/jccpsl.v25i2.8211

Received on: 20 June 2019

Accepted on: 30 June 2019

The ambit and thrust of public health are not as easy to delineate as of some other specialities (1). Public health professionals may therefore do well to ask their colleagues, from time to time, how they perceive their role in promoting public health. They will then discover how many mention 'engaging and encouraging members of the public to improve their own health', or something on those lines. A health promotional view of things (2) suggests that the public should play a major role in this task. But there probably will be some professionals and policy makers who'd doubt the benefit of this. Examining how Sri Lanka has succeeded in reducing tobacco consumption over the last few decades should help reduce their scepticism.

The total number of cigarettes legally sold in Sri Lanka has shown a marked decline over the last quarter century or so, from about 5.2 billion sticks in 1995 to less than 3.2 billion last year (3). Population increases and the more active distribution and marketing in areas where the armed conflict had previously been an obstacle, should have generated the opposite trend. This trend predates the important policy measures that came into force with the passing of the National Tobacco and Alcohol Authority Act (4) and is not explained by any decline in the affordability of cigarettes. There are sufficient grounds to say that enlightened public action was a major, and perhaps the biggest, driver of the trend (5). Public interest and involvement probably contributed to the passage of the 'NATA Act', following the WHO 'Framework
Convention on Tobacco Control' (6), and to the scope of the legislation being broadened to subject alcohol too to the same provisions as tobacco - an achievement not seen anywhere else in the world.

\section{Who was the public?}

'The public' is of course everyone. In this case, it was basically the critical mass of scattered people needed to precipitate change. Contributions from several sources multiplied their separate impacts. Nobody owned the enterprise and the disparate groups of people involved felt it was up to them - rather like how the 'yellow vests' in France operate today and the 'occupy' movement in the US tried a few years ago. The movement led by school children to generate action to forestall climate disaster is also growing on similar lines - this time global in ambition. All ownerless actions - in other words, owned by the public at large.

Although 'the public' is enormous and amorphous, interest and action generated by small groups of people in communication with each other can rapidly grow to become public property. Such groups could be said to constitute 'communities'. In matters of social change, these energized groups are initially outside the public mainstream, in a sense. But they are not opposed to wider society. The real opponents are the forces that covertly influence the 'wider public'- by manipulating shared desires and opinions through mass media; avenues of entertainment and leisure; news, information and academic sources and varied 'inter- 
personal' communications through individuals and agencies put in place for that very purpose.

\section{So, what did this public do?}

My view is that the public's success was due to different groups doing different things independently. They had time to learn from what worked, whilst doing their thing. They found, for instance, that lobbying for government action and policy measures initially led nowhere. In those early days, when no opposing body could hope to counter the overwhelming power of the tobacco trade, attempts to establish policies to promote the public's health were near impossible. There was, for instance, a tobacco industry representative even in the toothless committee dealing with tobacco control measures in the Health Department. Public representatives soon learned to ignore such official forums and concentrate on where they could produce a change.

Second, people learned to recognize determinants and address those they could effectively influence. Since it made sense to take on the vector, this determinant was pursued with great enthusiasm. Seeing what one group did to counter a tobacco trade action, made others want to emulate and outdo them. These initiatives developed further, by active members of the public copying what the trade did to counter them and using these tactics back on the vector. An example was the targeting and tarnishing of individuals active in tobacco control. While specific individuals working to reduce the spread of tobacco could be targeted, the tobacco trade (and its proxies) remained an impersonal entity, untouched by any counter activity. Shifting the blame from the tobacco trade in general to specific individuals, for the killing that cigarettes caused, was an important ingredient of success. Individuals who were in responsible positions or who were most active in spreading poisonous tobacco propaganda were identified by name. Since the majority of those working for the trade were people simply trapped in their jobs and unable to express their humane impulses due to the terms of their employment contracts, this shift of focus to specific vicious individuals was particularly salutary.

Another determinant that the public understood was the image of smoking. Helping young people to identify and reverse the various strategies used by the trade to promote a 'glamorous or cool image' was highly effective. Youth, and sometimes even children, were seen to be active, as part of the public. The image of smoking, especially among youth, changed steadily from 'bad, risky but cool' towards being seen as 'silly, unattractive and old-fashioned'. Smokers who were previously seen as being non-conformist and adventurous began to be seen more as failures - attempting to cover their deficiencies and low self-esteem behind a veil of smoke.

Communities campaigning for change found that most people were sensitive to the economic harm resulting from smoking. The extent of this harm was formally studied and reported only later (7-8) and these may even have been a result of the public awareness percolating to professional circles. The public readily took on the task of trying to minimize tobacco (and alcohol) expenditures as something that was more immediately felt than long term health harm.

\section{Local action, global potential}

Success in any enterprise is enhanced when those involved see positive outcomes from their efforts. Given the small-scale and scope of actions, it was possible for people to notice their successes. A change in attitude or conduct of the local tobacco retailer, a shift in how students of a particular school or village viewed smoking and the resistance to tobacco distributors who visited local retailers to replenish cigarette stocks are examples of short-term progress that people could see. When opportunities arose for them to share, the groups were keen to present their various successes as well as to learn from the successful approaches of others.

The development of sensitive indicators by which people involved could judge how they were progressing was probably a major motivator of continued actions, and these then led to more distant impacts being assessed. Groups of youth would, for example, monitor the number of cigarettes sold in a given week in their village outlet. Calculating the cash saved for the community served not only as an indicator but also as a stimulus to further effort.

What 'people action' created in circumscribed local settings led to a growing consciousness among 
the wider public about the viciousness of a trade that knowingly marketed a product which killed around half of its faithful customers. The customers too shifted away from being easily duped victims who gullibly supported their murderous supplier. I suspect that there was a shift in attitude within the tobacco trade too. Most of those employed in the trade had hitherto been unaware of the extent of harm caused by their product, taking cover behind the slogan that it was a legal and legitimate business. Many employees probably did not even know how their own business targeted young people. Their awakening may have contributed to dampening the company's vicious vigour.

\section{Other examples}

Reducing smoking is only one example of a public health achievement in which the Sri Lankan public played a substantial role. Alcohol consumption is another area - where public action had brought about significant changes in numerous settings. In addition, people in various scattered communities successfully challenged the use of 'drunkenness' as an excuse for being rude or aggressive. A further area where public action played a strong role was in preventing suicides. A component of the National Policy on Suicide (9) that began to be implemented in the late 1990s required that the mass media stop reporting suicides in ways that could encourage further harm - such as through 'copycat' acts by vulnerable individuals. The level to which different media agencies cooperated differed considerably. Television channels and newspapers that were insistent in continuing their previous forms of reporting were directly addressed by well-informed and committed members of the public - and this contributed strongly to these media agencies too eventually modifying their previous stance. A further component of the suicide prevention effort was reducing easy access to highly lethal pesticides. Engagement of the public resulted in enthusiastic individuals taking the initiative (in many paddy cultivation areas) to implement their own measures in this regard. The notable reduction in suicides since then was undoubtedly driven by these public efforts too. More recently there are many examples of pubic action leading to gains in chronic non-communicable disease prevention (10-11).

\section{Lessons and conclusions}

The public may be the best engine to drive many, or most, public health initiatives. For this potential to be fulfilled, an approach that allows communities to lead, where relevant, is needed. People may then understand, analyse and address the determinants that they can change. Creating public awareness is, alone, rarely sufficient to engage and enthuse people to take the lead in this kind of initiative. To nurture such public processes, we have to acquire not only the skills needed. A supportive mindset too is required. This is present in each of us to different degrees. A collective effort can enhance the further development of this mindset.

Should the public health community become more active in engaging and mobilizing the public, we may see other problems too being even better addressed by this means. Preventing violence - between individuals and between groups - is an example. Similarly, improving nutrition, reducing non-communicable diseases, controlling the spread of dengue, minimizing the transmission of sexually transmitted diseases, enhancing child development, reducing sexual abuse, fostering happier family life and many other goals are better reachable through public action. Issues further afield such as the prevention of corruption and controlling the actions of politicians and law enforcers may too, eventually, be won through public action.

The time will likely come when public health professionals see their role as mainly to awaken, inform and guide people to improve their own wellbeing. I look forward to the day when the professional community accepts as guiding inspiration the tenet, 'Public health is public property'.

Declaration of the author: Diyanath Samarasinghe holds token shares in the tobacco company to enhance the effectiveness of his tobacco control activities, but does not trade in them or encash the resultant dividends.

\section{References}

1. Rajapaksa L. Who are we? Journal of the College of Community Physicians of Sri Lanka 2018; 23(4): 99-101.

2. WHO. Ottawa Charter for Health Promotion. Geneva: World Health Organization, 1986. No: WHO/HPR/HEP/ 95.1. 
3. Alcohol and Drug Information Centre (ADIC) Sri Lanka. Alcohol and Tobacco Related Facts in Sri Lanka. Archived Database, 2019.

Available from: http://adicsrilanka.org/.

4. Parliament of the Democratic Socialist Republic of Sri Lanka. National Authority on Tobacco and Alcohol Act, No 27 of 2006. Colombo: Government of the Democratic Socialist Republic of Sri Lanka, 2006.

5. Samarasinghe $\mathrm{D} \&$ Gooneratne $\mathrm{C}$. Tobacco related harm in South Asia. British Medical Journal 2004; 328 (7443): 780 .

6. WHO. Framework Convention on Tobacco Control 2003 (updated reprint 2004). Geneva: World Health Organization, 2005.

7. Perera K, Guruge G, Jayawardana P. Household expenditure on tobacco consumption in a povertystricken rural district in Sri Lanka. Asia Pacific Journal of Public Health 2017; 29(2): 140-148.

8. De Silva V, Samarasinghe D, Hanwella R. Association between concurrent alcohol and tobacco use and poverty. Drug and Alcohol Review 2011; 30(1): 69-73.

9. The Presidential Committee on Prevention of Suicide. National Policy and Action Plan on Prevention of Suicide 1997. WHO MiNDbank

Available from: https://www.mindbank.info/item/6096.

10. Samarasinghe D, Amunugama S, Arambepola C, Fernando M, Wijeyaratne C. Empowering communities to reduce the burden of diabetes and cardiovascular disease risk: lessons from the NIROGI Lanka project in Sri Lanka. WHO Regional Health Forum 2013; 17(1): 53-60.

11. Gunawardena N, Kurotani K, Indrawansa S, Nonaka D, Mizoue T, Samarasinghe D. School-based intervention to enable school children to act as change agents on weight, physical activity and diet of their mothers: a cluster randomized controlled trial. International Journal of Behavioural Nutrition and Physical Activity 2016; 13: 45. 